\title{
Effect of supercritical fluid density on nanoencapsulated drug particle size using the supercritical antisolvent method
}

This article was published in the following Dove Press journal:

International Journal of Nanomedicine

24 April 2012

Number of times this article has been viewed

\section{Mahshid Kalani \\ Robiah Yunus}

Chemical and Environmental Engineering, Faculty of Engineering, University Putra Malaysia,

Selangor Darul Ehsan, Malaysia
Correspondence: Mahshid Kalani Institute of Advanced Technology, Universiti Putra Malaysia, 43400 Serdang Selangor, Darul Ehsan, Malaysia

Tel +6038946629

Fax +60386567120

Email mahshid.kalani@gmail.com

\begin{abstract}
The reported work demonstrates and discusses the effect of supercritical fluid density (pressure and temperature of supercritical fluid carbon dioxide) on particle size and distribution using the supercritical antisolvent (SAS) method in the purpose of drug encapsulation. In this study, paracetamol was encapsulated inside L-polylactic acid, a semicrystalline polymer, with different process parameters, including pressure and temperature, using the SAS process. The morphology and particle size of the prepared nanoparticles were determined by scanning electron microscopy and transmission electron microscopy. The results revealed that increasing temperature enhanced mean particle size due to the plasticizing effect. Furthermore, increasing pressure enhanced molecular interaction and solubility; thus, particle size was reduced. Transmission electron microscopy images defined the internal structure of nanoparticles. Thermal characteristics of nanoparticles were also investigated via differential scanning calorimetry. Furthermore, X-ray diffraction pattern revealed the changes in crystallinity structure during the SAS process. In vitro drug release analysis determined the sustained release of paracetamol in over 4 weeks.
\end{abstract}

Keywords: supercritical antisolvent, encapsulation, supercritical fluid density, particle size

\section{Introduction}

The use of supercritical fluid (SCF) is an effective and clean method in the production of encapsulated particles. The pressure and temperature of SCF are greater than its critical pressure and temperature while it remains as a single phase. The SCF techniques modify the particle size, distribution, and morphology. The major advantage of supercritical antisolvent (SAS) techniques is that the solvent can be efficiently removed. Furthermore, it is a single-step process and a clean and effective method for nanoencapsulation, and the mild operation temperature avoids thermal degradation. Supercritical solvation power can be readily controlled by adjusting either temperature or pressure; thus, it can be used for selective crystallization and control of particle morphology or crystalline forms. ${ }^{1-3}$

The conventional processes for encapsulation such as milling, solvent evaporation and spray drying cannot produce fine and pure particles. Particles that are produced by milling method have a large distribution range. Solvent/emulsion evaporation techniques cannot completely remove solvent from the particles, and the spray drying process can thermally denaturate compounds. ${ }^{4}$

During the SAS processes, the mass transfer between SCF and solution happens very quickly because of very high diffusion of SCF in the solution, which results in 
the expansion of solution. Therefore, the solubility power is decreased, and a supersaturated solution results in precipitation.

The density of SCF affects mass transfer between organic solvent and SCF during precipitation. The density of SCF depends on the temperature and pressure values of the fluid..$^{5-8}$ This work has studied the effect of temperature and pressure on particle size and distribution produced by the SAS process.

SAS precipitation description should include important contributions from precipitation kinetics, thermodynamics, and fluid dynamics. Furthermore, study of phase behavior is key in this area.

\section{Materials and methods}

Poly-L-lactic acid used in this study (inherent viscosity $2.0 \mathrm{dL} / \mathrm{g}$, as reported by the supplier), as the biodegradable polymer, was obtained from Sigma-Aldrich (St, Louis, MO). Paracetamol (99.9\%) was obtained from the Faculty of Medicine and Health Science, UPM, Malaysia. Methylene chloride (purity 99.8\%) high-performance liquid chromatography grade, as solvent for biodegradable polymer, was obtained from Sigma-Aldrich. Acetone (purity 99.8\%) high-performance liquid chromatography grade, as solvent for paracetamol, was obtained from Fisher Scientific (Loughborough, UK). Purified grade carbon dioxide $\left(\mathrm{CO}_{2}\right)$ was used as the SCF.

\section{Preparation of nanoparticles}

The SAS apparatus consisted of a high-pressure pump (Thar SCF P-50A) and a metering pump (Chrom Tec Series III) used to deliver the supercritical $\mathrm{CO}_{2}$ and feed solution, respectively. During the SAS process, supercritical $\mathrm{CO}_{2}$ fluid diffused and evaporated in the gas phase. Therefore, the density of the solvent decreased and precipitation occurred. The very fast mass transfer between the liquid phase and SCF reduced the surface tension and controlled droplet shape. A stainless steel cylindrical vessel of $490 \mathrm{~mL}$ was used as a precipitation chamber. The liquid solution (composed of poly-L-lactic acid and paracetamol [2:1] dissolved in the mixture solvent of dichloromethane and acetone [7:4]) was delivered to the precipitation chamber with a constant flow rate equal to $1.75 \mathrm{~mL} /$ minute through a $2 \mu \mathrm{m}$ diameter stainless steel nozzle. A chiller (Thermo Scientific) and a heat exchanger were used to liquify $\mathrm{CO}_{2}$ from a gas cylinder when the chiller temperature dropped to $3{ }^{\circ} \mathrm{C}$ and the $\mathrm{CO}_{2}$ was delivered through another inlet port located on the top of the precipitator. The temperature of precipitation chamber was controlled using a water bath in the varied range equal to $30^{\circ} \mathrm{C}, 35^{\circ} \mathrm{C}, 40^{\circ} \mathrm{C}, 45^{\circ} \mathrm{C}, 50^{\circ} \mathrm{C}$, and $55^{\circ} \mathrm{C}$. The pressure of the precipitator was regulated by a micrometering valve located at the exit of the chamber in the varied range equal to 80 bar, 90 bar, 100 bar, 110 bar, and 120 bar. The produced particles were collected in the precipitator chamber. The SAS apparatus is shown in Figure 1.

\section{Observation and characterization Scanning electron microscopy}

Scanning electron microscopy (SEM) (Hitachi S-3400 N) was used to characterize the morphology and particle size of the nanoencapsulated particles. The sample was adhered to the adhesive carbon tape on an aluminum stub and coated with gold-palladium. The morphology of the samples was characterized using SEM, and images were taken from a variety of areas of the samples on the stub. Particle size and their distributions were determined using the UTHSCSA Image Tool software, Version 3.00 program, based on the SEM micrographs. More than 500 particles from each sample were taken for image processing.

\section{Transmission electron microscopy}

Transmission electron microscopy (TEM) (LEO 912AB) was used to characterize the internal structure of nanoencapsulated particles. One drop of sample was placed on a copper grid and dried. Then, the copper grid was scanned with TEM for investigation of the internal structure.

\section{Energy dispersive $\mathrm{X}$-ray spectroscopy}

Element compositions were investigated using a NORAN SYSTEM 6.0 (Thermo Scientific). It was followed with an acquisition time of approximately 5 minutes at $20 \mathrm{KV}$.

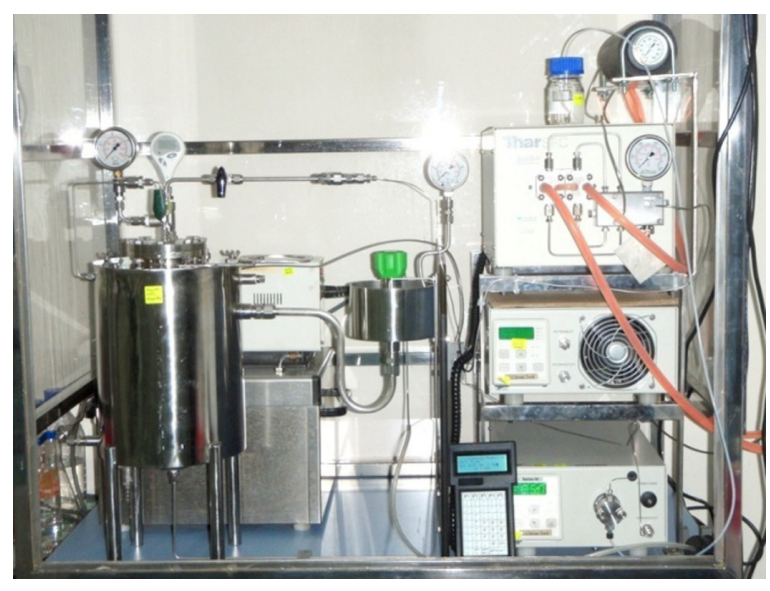

Figure I Equipment set-up used in this study for supercritical antisolvent system. 

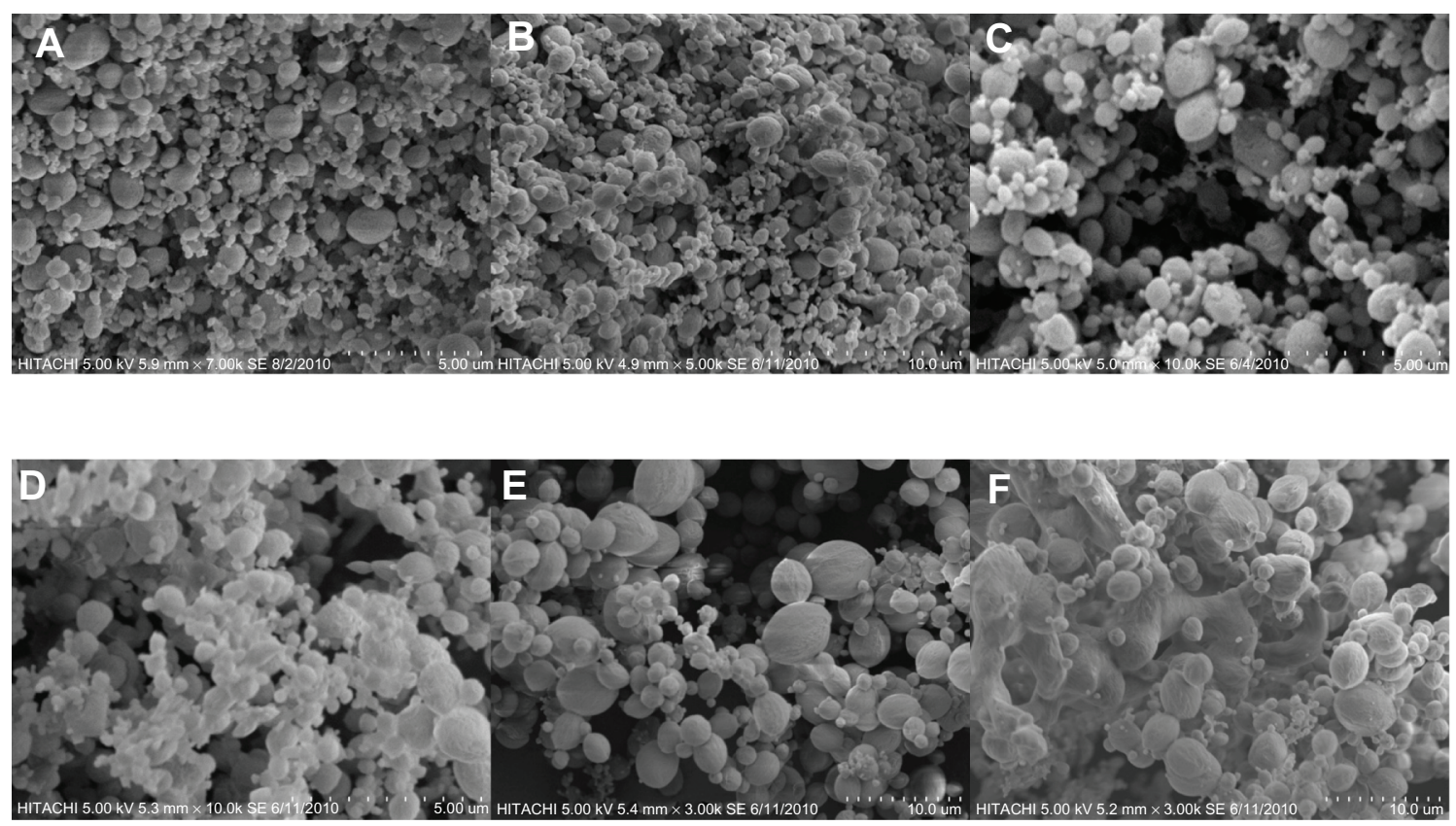

Figure 2 Scanning electron microscopy micrographs of nanoencapsulated paracetamol inside L-polylactic acid at 120 bar and different temperatures: (A) $30^{\circ} \mathrm{C}$, (B) $35^{\circ} \mathrm{C}$, (C) $\left.40^{\circ} \mathrm{C}, \mathbf{D}\right) 45^{\circ} \mathrm{C},(\mathrm{E}) 50^{\circ} \mathrm{C},(\mathbf{F}) 55^{\circ} \mathrm{C}$.

\section{Differential scanning calorimetry}

A weighted sample more than $5 \mathrm{mg}$ was collected in an aluminum pan (Al-Crucibles $40 \mu \mathrm{L}$ ) and sealed completely. The system was purged with nitrogen (gas control Ts $0800 \mathrm{GC} 1$ ) to prevent oxidation or other undesired reactions. The analysis of samples was performed in the temperature range of $0^{\circ} \mathrm{C}-200^{\circ} \mathrm{C}$ at the rate of $2^{\circ} \mathrm{C} / \mathrm{min}$.

\section{X-ray diffraction pattern}

The X-ray diffractograms were recorded by Shimadzo XRD-6000 equipment with Ni-filtered $\mathrm{Cu}-\mathrm{K} \alpha$ radiation.
The operating conditions were $20 \mathrm{~mA}$ and $40 \mathrm{KV}$ at room temperature. The X-ray diffractograms were recorded with the scan rate of $4 \mathrm{~s} / \mathrm{step}$ and step width $0.05^{\circ}$.

\section{In vitro drug release}

A total of $25 \mathrm{mg}$ of nanoparticles was placed into $50 \mathrm{~mL}$ of phosphate buffered saline (PBS) ( $\mathrm{pH} 7.4$ ) containing $0.025 \%$ sodium azide. The sample was placed in a shaking incubator maintained at $50 \mathrm{rpm}$ and $37^{\circ} \mathrm{C}$. The paracetamol released into the medium PBS was analyzed using an ultravioletvisible spectrometer (Shimadzu Model 1650-PC, Japan).

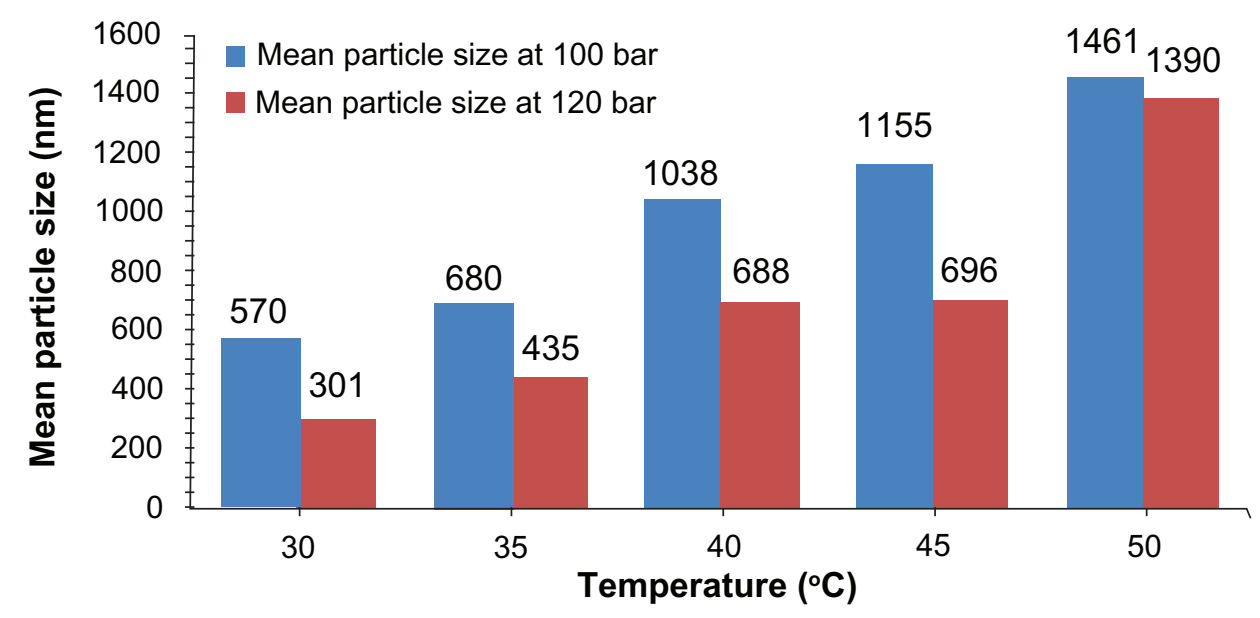

Figure 3 Effect of temperature on particle size. 

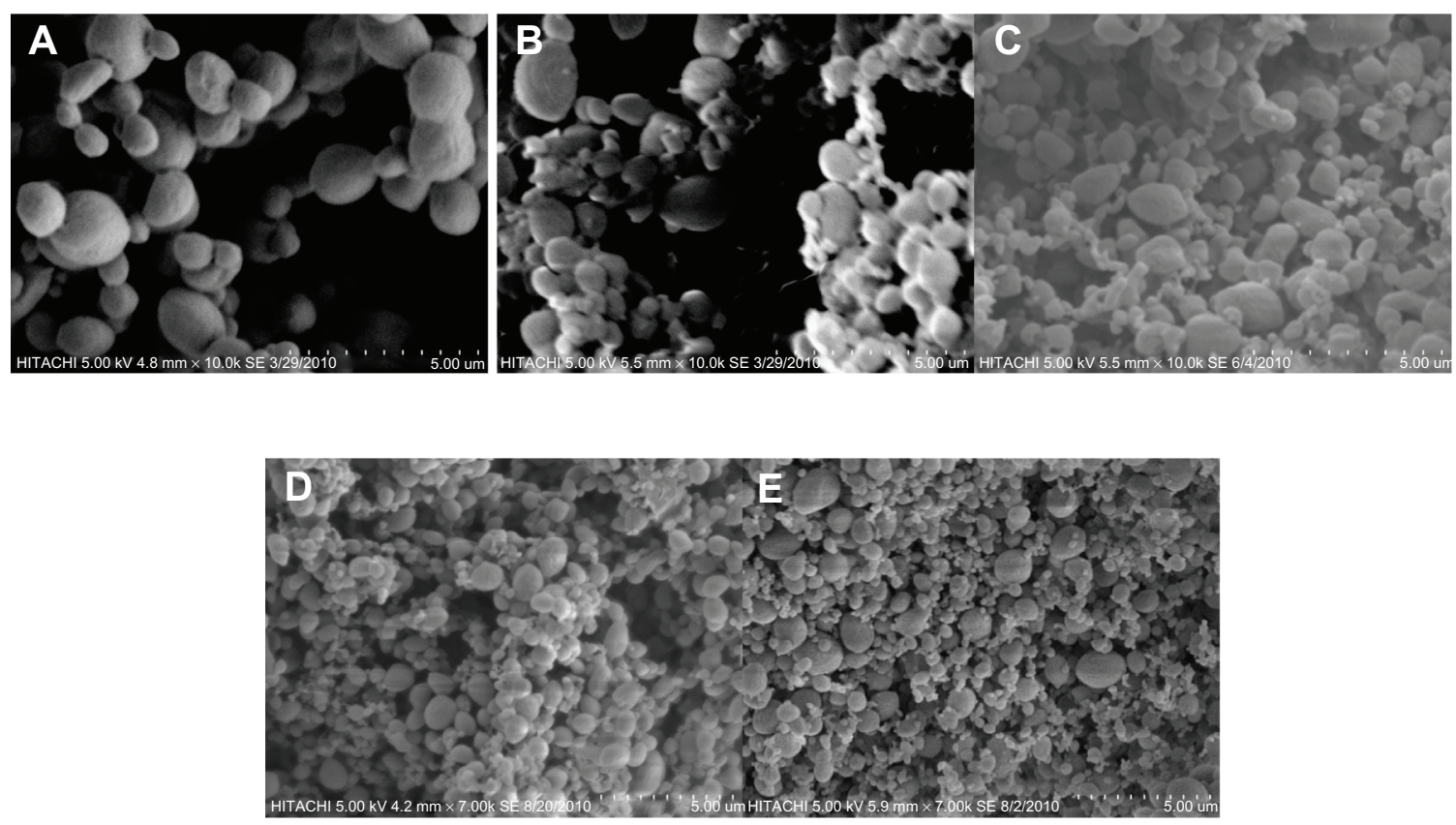

Figure 4 Scanning electron microscopy micrographs of nanoencapsulated paracetamol inside L-polylactic acid at $30^{\circ} \mathrm{C}$ and different pressures: (A) 80 bar, (B) 90 bar, (C) 100 bar, (D) 110 bar (E) 120 bar.

\section{Results and discussion}

\section{Particle size, morphology, and internal} structure of nanoparticles

SEM micrographs of products produced in the temperature below $45^{\circ} \mathrm{C}$ show fine spherical particles with all different pressures. By increasing the temperature and thus decreasing the density, the particle size increases due to the plasticizing effect. Supercritical $\mathrm{CO}_{2}$ decreases the glass transition temperature of biodegradable polymers, acting like a plasticizer. Therefore, the polymer with a low glass transition temperature tends to form sticky and aggregated particles..$^{9,10}$ At temperatures higher than $45^{\circ} \mathrm{C}$, which is near the glass transition temperature of polymers, the particles are agglomerated, and large and nonspherical particles are formed. ${ }^{11}$ The glass transition temperature of some polymers may be decreased after contact with SCF due to taking the place of $\mathrm{CO}_{2}$ for a very short time because of intermolecular interaction between the biodegradable polymer and dissolved SCF. ${ }^{12}$ The effect of temperature on particle size and their morphology at 120 bar is shown in Figure 2. The same results occur with other pressures (Figure 3).

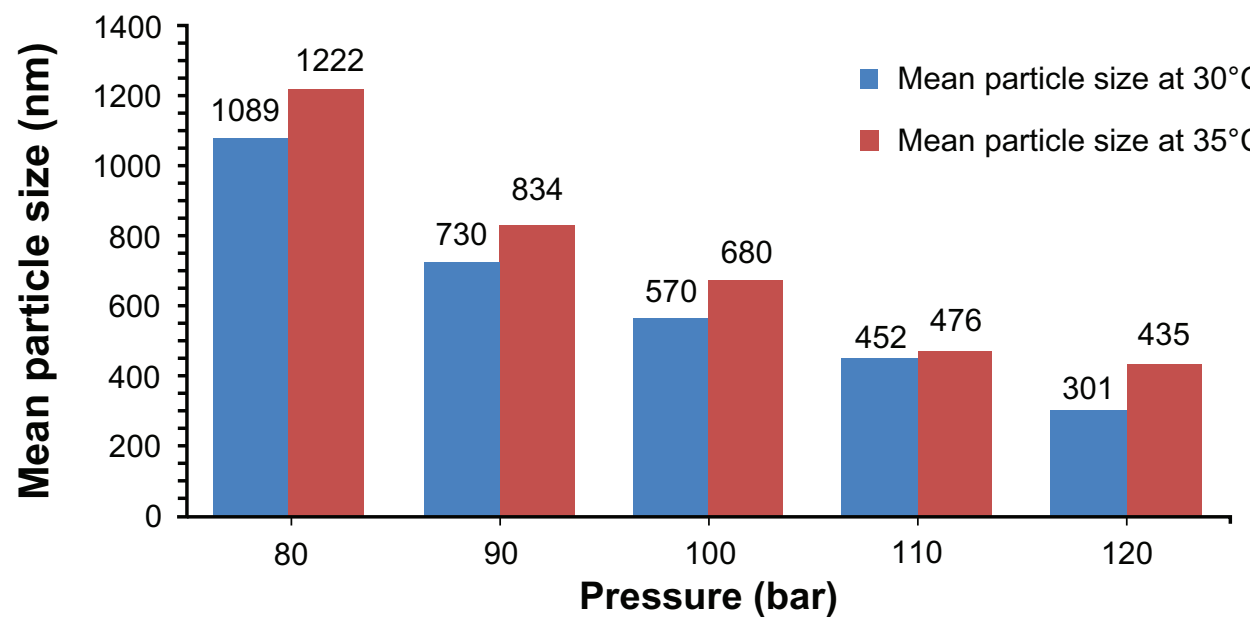

Figure 5 Effect of pressure on particle size. 


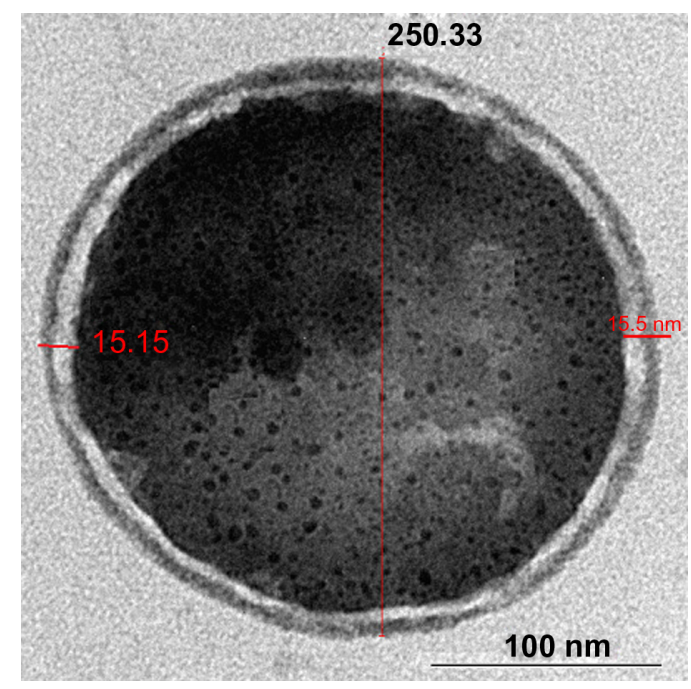

Figure 6 Internal structure of nanoparticles.

Also, the particles size is reduced through pressure enhancement. In fact, the solubility of solute in the supercritical $\mathrm{CO}_{2}$ depends on the density. Density increment enhances the molecular interaction and thus the solubility. The effect of density on solubility is more considerable at higher densities. ${ }^{13}$

SEM micrographs of products in different pressures at $30^{\circ} \mathrm{C}$ are shown in Figure 4. The same results occur with other pressures (Figure 5).

Other important factors in respect of particle size are nucleation process and rapid mass transfer of antisolvent and solvent leading to high supersaturations for the solute, which results in rapid nucleation and growth of more than one particle per primary droplet. ${ }^{13,14}$

The TEM images revealed the encapsulation of paracetamol inside biodegradable polymer, as shown in Figure 6.

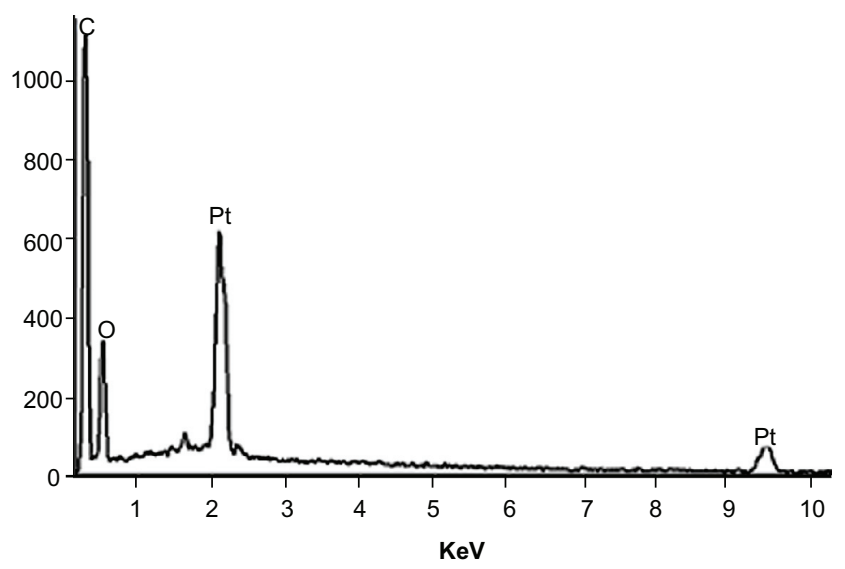

Figure 7 Energy dispersive X-ray spectroscopy of nanoparticles revealed the completed washing step.
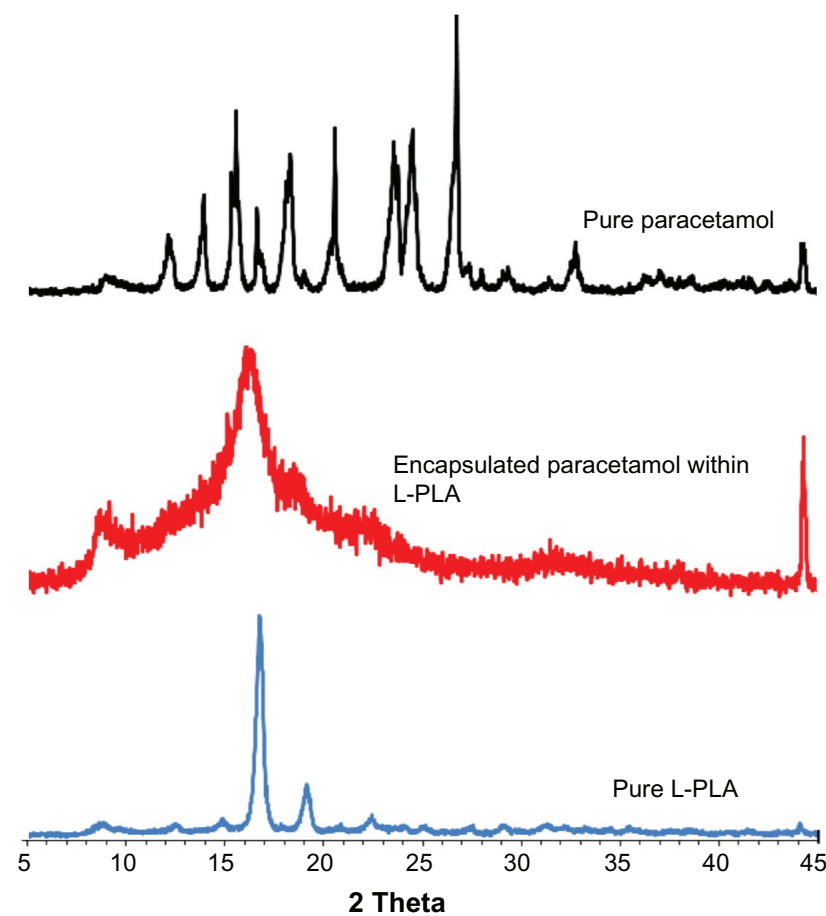

Figure 8 X-ray diffraction pattern of pure L-polylactic acid (L-PLA), pure paracetamol, and encapsulated paracetamol inside L-PLA.

In order to control the washing step, energy dispersive X-ray spectroscopy characterization was carried out (Figure 7). During the observation with SEM, the electron beams were directed toward the sample and emitted X-rays were examined. The position of X-ray peaks reveals the elements available in the sample. No peaks related to chlorine arising from Di-chloromethan (methylene chloride) solvent in the spectrum of sample were detected. Therefore, the methylene chloride solvent was completely removed from products during the washing step.

\section{Structure of nanoparticles}

Based on the diffraction patterns, it is distinguished that the based peak of nanoparticle crystallographs are equal to pure polymer $\left(16.64^{\circ}\right)$ due to the higher ratio of polymer over paracetamol in the initial solute (Figure 8). Furthermore, the crystallinity structure changes during the SAS process due to the very fast mass transfer during the SAS process and produces particles that precipitate very quickly. Therefore, there is not sufficient time to produce particles in the crystal structure. The change in crystallinity is observed on both the X-ray diffraction pattern (Figure 8) and differential scanning calorimetry (DSC) thermograms (Figure 9). The intensity of crystallinity peaks of nanoencapsulated particles obviously reduced in DSC thermograms. Based on the surface area of exothermal 


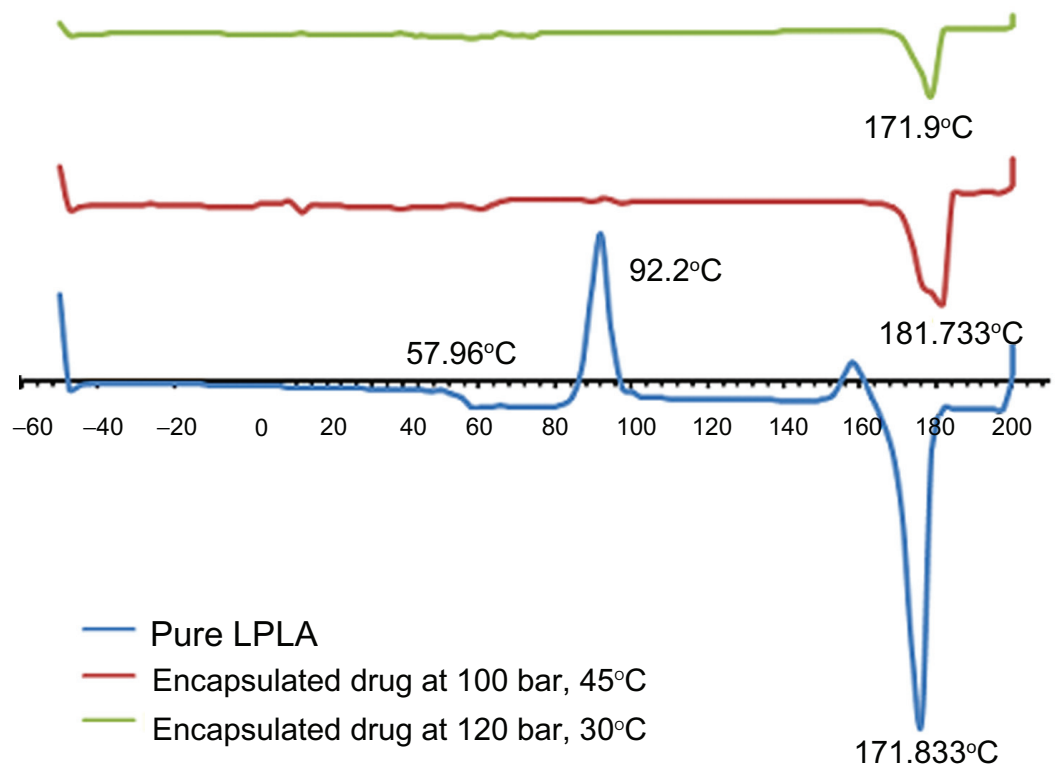

Figure 9 The comparison of melting point and crystallinity of pure L-polylactic acid and nanoparticles produced in different conditions.

peak and endothermal peak, the percentage of crystallinity in this polymer can be distinguished. In the crystalline phase of polymer, the atoms are arranged regularly; thus, it absorbed a huge energy to break the crystalline structure, but during the melting process the energy was released. The degree of crystallinity is obtained as follows:

$$
\frac{\Delta H m-\Delta H c}{\Delta H m_{0}} \times 100=\text { Percentage of crystallinity }
$$

where $\Delta H m$ is the enthalpy of fusion and is determined by the area integration of the melting peak $(71.18 \mathrm{~J} / \mathrm{gr})$,
$\Delta H c$ is the heat of crystallinity and is determined by the area integration of the crystallinity peak $(30.24 \mathrm{~J} / \mathrm{gr})$, and $\Delta H m_{0}$ is the enthalpy of fusion of the completely crystalline material or corresponds to an infinite thickness of crystal equal to $81.3 \mathrm{~J} / \mathrm{gr}$. The crystallinity of pure polymer is equal to $50.35 \%$ based on the DSC thermogram.

\section{In vitro drug release analysis}

Sustained release of paracetamol in PBS buffer was investigated over 4 weeks. The first burst happened after 1 week and the cumulative paracetamol release versus time is shown in Figure 10. The kinetic of releasing is fitted with a

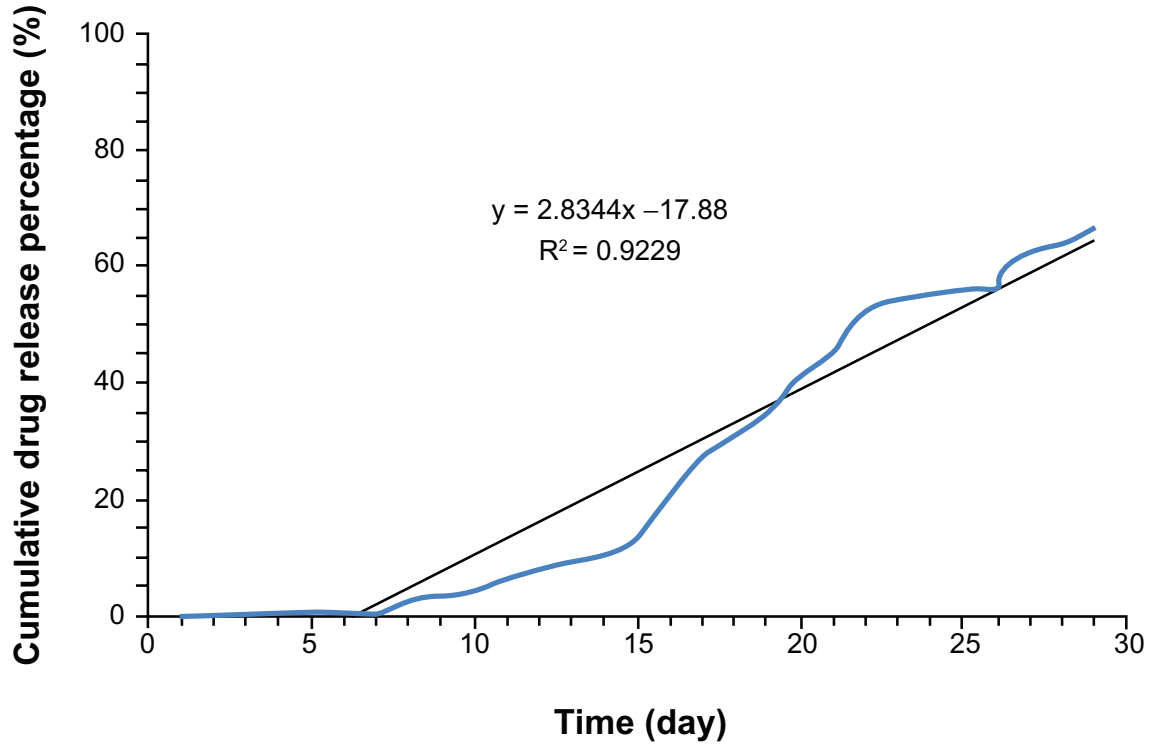

Figure 10 In vitro release profile of paracetamol encapsulated in L-polylactic acid based on the zero-order model. 


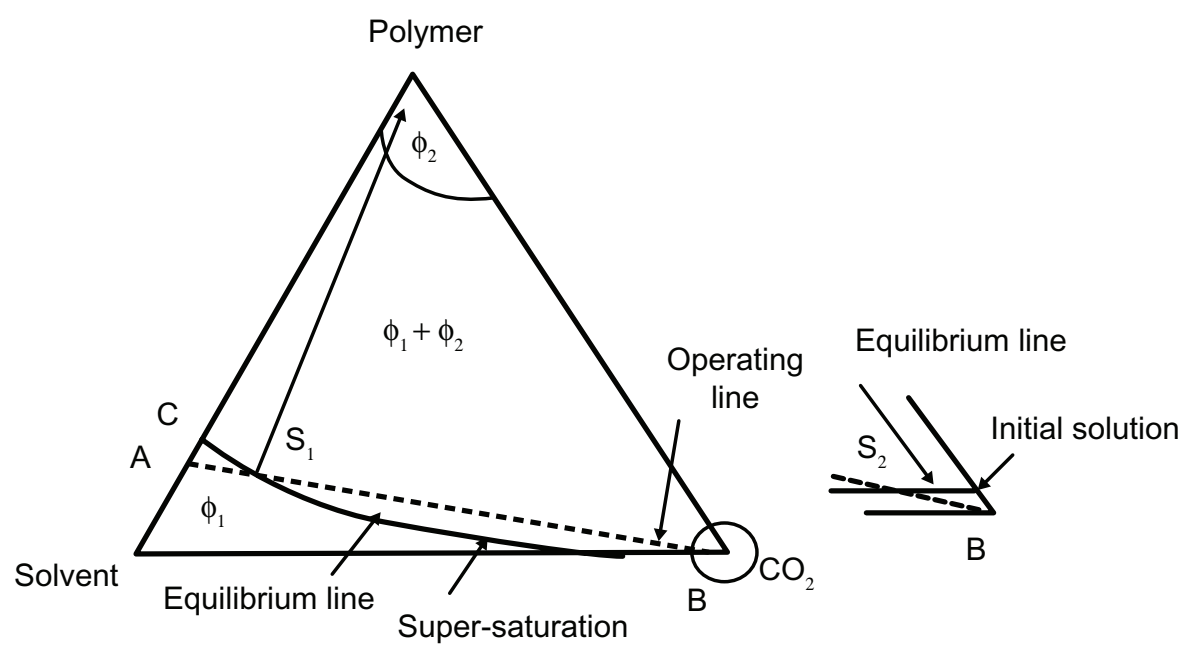

Figure I I Ternary system for the supercritical antisolvent method.

Note: Reprinted from Yulu W, Dave RN, Pfeffer R. Polymer coating/encapsulation of nanoparticles using a supercritical anti-solvent process.J Supercrit Fluids. 2004;28:85-99, Copyright 2004, with permission from Elsevier Limited. ${ }^{18}$

zero-order model based on R-square (92.2\%). The zero-order kinetic model Eq (2), shows that the drug release rate is independent of its concentration: ${ }^{15}$

$$
\mathrm{C}=\mathrm{K} \cdot \mathrm{t}
$$

where $\mathrm{K}$ is zero-order rate constant expressed and $\mathrm{t}$ is the time.

\section{Conclusion}

The antisolvent SCF process is a suitable process for pharmaceutical application, and it is possible to control the particle size and its distribution and the shapes and structure of particles in a wide range by adjusting the process parameter and choosing a suitable biodegradable polymer. ${ }^{16}$ For the SAS process the ternary system is shown in Figure 11.

According to this diagram, $\phi_{1}$ is the one-phase region in which the biodegradable polymer dissolves in the solvent. In this region, $\mathrm{CO}_{2}$ may also dissolve in the solution. The $\phi_{2}$ region shows the glassy region, which is a polymerrich phase. In this region the limited amount of solvent and $\mathrm{CO}_{2}$ makes a solution with polymer. In the two-phase regions $\left(\phi_{1}+\phi_{2}\right)$, both a solvent-rich phase and a polymer-rich phase exist and are in equilibrium. The curve line from point $\mathrm{C}$ to point B shows the polymer solubility in both solvent and SCFs. The polymer solute feeding to SCF is shown with a straight line. By adding the solution to supercritical $\mathrm{CO}_{2}$ fluid $\left(\mathrm{ScCO}_{2}\right)$, the small amount of the solute dissolves in the $\mathrm{ScCO}_{2}$ (in $\phi_{1}$ region); the process continues until the saturation point of the solute in the mixture of the solvent and $\mathrm{ScCO}_{2}$, the supersaturation point, is reached. Finally, by adding more solute into the SCF, the supersaturation and then the phase transition will take place.
The process conditions during solute spraying can change the properties of biodegradable polymer such as viscosity; thus, the precipitation occurs. It is crucial that the precipitation rate be lower than the atomization rate to produce desirable particle sizes and morphology. In addition, the biodegradable polymer must precipitate during spraying due to avoiding polymeric droplet production and agglomeration. ${ }^{13,17}$ Increasing the density enhances the molecular interaction and thus the solubility, and this effect is even more sensitive at higher densities. To sum up, this study realized that increasing pressure and decreasing temperature can improve particle size and morphology. Furthermore, it is distinguished that crystallinity structure changes during the SAS process. The nanoparticles showed very slow drug release in a buffer solution.

\section{Disclosure}

The authors report no conflicts of interest in this work.

\section{References}

1. Bristow S, Shekunov T, Yu B, York P. Analysis of the supersaturation and precipitation process with supercritical $\mathrm{CO}_{2} . J$ Supercrit Fluids. 2001;21:257-271.

2. Byrappa K, Ohara S, Adschiri T. Nanoparticles synthesis using supercritical fluid technology - towards biomedical applications. Adv Drug Deliv Rev. 2008;60:299-327.

3. Kikic I, Vecchione F. Supercritical impregnation of polymers. Current Opinion in Solid State and Materials Science. 2003;7:399-405.

4. Rantakyl M, Jnitti M, Aaltonen O, Hurme M. The effect of initial drop size on particle size in the supercritical anti-solvent precipitation (SAS) technique. J Supercrit Fluids. 2002;24:251-263.

5. Spasić AM. Finely Dispersed Particles: Micro-, Nano-, and AttoEngineering. New York: Taylor and Francis; 2006.

6. Yu B, Shekunov T, Baldyga J, York P. Particle formation by mixing with supercritical anti-solvent at high Reynolds numbers. Chem Eng Sci. 2001;56:2421-2433. 
7. Sze Tu L, Dehghani F, Foster NR. Micronisation and microencapsulation of pharmaceuticals using a carbon dioxide anti-solvent. Powder Technology. 2002;126:134-149.

8. Gupta RB. Nanoparticle Technology for Drug Delivery. Drugs and the Pharmaceutical Sciences. New York: Taylor and Francis Group; 2006.

9. Kikic I, Vecchione F. Supercritical impregnation of polymers. Curr Opin Solid State Mater Sci. 2003;7:399-405.

10. Kawashima Y. Drug delivery applications of supercritical fluid technology. Adv Drug Deliv. 2008;2.

11. Reverchon E, Antonacci A. Polymer microparticles production by supercritical assisted atomization. J Supercrit Fluids. 2007;39:444-452.

12. Cocero MJ, Martin A, Mattea F, Varona S. Encapsulation and coprecipitation processes with supercritical fluids: Fundamentals and applications. J Supercrit Fluids. 2009;47:546-555.

13. Kalani M, Yunus R. Application of supercritical anti-solvent method in drug encapsulation: a review. Int J Nanomedicine. 2011;6:1429-1442.
14. Lengsfeld CS, Delplanque J, Barocas VH, Randolph TW. Mechanism governing microparticle morphology during precipitation by a compressed anti-solvent: atomization vs nucleation and growth. JPhys Chem B. 2000;104(12):2725-2735.

15. Shoaib MH, Tazeen J, Merchant HA, Yousuf RI. Evaluation of drug release kinetics from ibuprofen matrix tablets using HPMC. Pak J Pharm Sci. 2006;19(2):119-124.

16. Jung J, Perrut M. Particle design using supercritical fluids: literature and patent survey. J Supercrit Fluids. 2001;20:179-219.

17. Hao J, Whitaker MJ, Serhatkulu G, Shakesheff KM, Howdle SM. Supercritical fluid assisted melting of poly(ethylene glycol): a new solventfree route to microparticles. J Mater Chem. 2005;15:1148-1153.

18. Yulu W, Dave RN, Pfeffer R. Polymer coating/encapsulation of nanoparticles using a supercritical anti-solvent process. J Supercrit Fluids. 2004;28:85-99.
International Journal of Nanomedicine

\section{Publish your work in this journal}

The International Journal of Nanomedicine is an international, peerreviewed journal focusing on the application of nanotechnology in diagnostics, therapeutics, and drug delivery systems throughout the biomedical field. This journal is indexed on PubMed Central, MedLine, CAS, SciSearch $\AA$, Current Contents ${ }^{\circledR} /$ Clinical Medicine,

\section{Dovepress}

Journal Citation Reports/Science Edition, EMBase, Scopus and the Elsevier Bibliographic databases. The manuscript management system is completely online and includes a very quick and fair peer-review system, which is all easy to use. Visit http://www.dovepress.com/ testimonials.php to read real quotes from published authors. 